\title{
COLON CANCER
}

\section{Prognostic significance of the allelic loss of the BRCA1 gene in colorectal cancer}

\author{
J M Garcia, R Rodriguez, G Dominguez, J M Silva, M Provencio, J Silva, A Colmenarejo, I Millan, \\ C Muñoz, C Salas, S Coca, P España, F Bonilla
}

See end of article for authors' affiliations

Correspondence to

DrF Bonilla, Department of Medical Oncology,

Hospital Universitario

Puerta de Hierro, C/San

Martin de Porres, 4 ,

28035-Madrid, Spain;

felixbv@stnet.es

Accepted for publication 8 July 2003
Background: Survival at the intermediate stage of colorectal cancer (CRC) is less predictable than in the early and advanced stages. Several genetic markers possibly involved in growth and progression of CRC can be used for prognosis.

Aims: This study investigated the proportion of allelic loss (loss of heterozygosity (LOH)) at the BRCA1 locus in sporadic CRC and its value in patient prognosis.

Patients and methods: A total of 314 patients were investigated for $\mathrm{LOH}$ at the BRCA1 locus using polymerase chain reaction by means of three intragenic polymorphic microsatellite markers. Allelic losses were compared with clinicopathological characteristics of patients, recurrence rate, disease free survival (DFS), and overall survival.

Results: Twenty six patients were excluded because of microsatellite instability. Of the remaining 288 cases, 244 (84.7\%) were informative, with 97 (39.8\%) patients bearing BRCA1 LOH. Recurrence rate was higher in patients with $\mathrm{LOH}(p=0.0003)$, and DFS was $73.3 \%$ (SEM 5.7) at five years in patients without $\mathrm{LOH}$, and $49.2 \%(7.1)$ in cases with positive allelic loss $(p=0.0004)$. Retention of alleles at the BRCA1 locus was associated with a favourable DFS in stages I and II $(p<0.05)$. The presence of $\mathrm{LOH}$ was also significantly associated with short overall survival $(p=0.02)$. Multivariate analysis in the complete series showed that stage $(p=0.006)$ and lymph node metastases ( $\geqslant 4$ nodes, $p=0.0001 ; 1-3$ nodes, $p=0.038$ ) were independent prognostic factors. However, multivariate study by stages revealed that BRCA1 LOH was an independent prognostic factor in stages I and II $(p=0.001)$.

Conclusions: BRCA1 $\mathrm{LOH}$ is a molecular alteration present in $\mathrm{CRC}$, with unfavourable repercussions for overall survival, that could be considered as an outstanding independent prognostic factor in stages I and II.
Abbreviations: CRC, colorectal cancer; LOH, loss of heterozygosity; DFS, disease free survival; CEA, carcinoembryonic antigen; PCR,

ovarian cancers is established. Mutations in this gene are responsible in part for the inherited predisposition to breast and ovarian cancers, and probably for one third of all site specific breast cancer kindreds. ${ }^{20}$ However, whether these mutations are a factor in sporadic forms of these tumours remains unclear. It has been suggested that members of families linked to the BRCAl gene have a higher than normal risk of CRC and prostate cancer, with relative risks of 3.3 and 2.95 , respectively. ${ }^{21}$

In a previous study, we found a high percentage $(49 \%)$ of $\mathrm{LOH}$ in the $17 \mathrm{q} 21$ region in sporadic CRC cases. Seven polymorphic markers of this region were studied and no cases displayed loss of the all informative markers, suggesting that losses in this region were not due to loss of the entire chromosome. ${ }^{22}$ In this series we also studied the LOH status of locus TP53, to determine the status of chromosome 17 and the relation between concomitant $\mathrm{LOH}$ at the two loci.

The present study investigated $\mathrm{LOH}$ at the $17 \mathrm{q} 21$ region using three microsatellite markers intragenic to the BRCAl gene in a series of sporadic CRCs with unknown status with respect to mutations in germline BRCAl. The clinical relevance of $17 \mathrm{q} 21$ allelic losses was analysed in a study comparing them with clinicopathological characteristics, to determine their value as a prognostic factor and influence on disease free survival (DFS) and overall survival. related to the transactivation region of the protein ${ }^{16}$ and idues $758-1064$ to the domain binding to $\operatorname{Rad} 51,{ }^{17}$ thus breaks ${ }^{18}$ In relation to its repair role $\mathrm{BRCAl}$ is also related to coactivation of p53. ${ }^{19}$ The relationship of truncating germline mutations in the BRCAl gene and breast and polymerase chain reaction; MI, microsatellite instability 


\section{PATIENTS AND METHODS}

\section{Patients, tumour samples, and DNA extraction}

The present study, approved by the research ethics boards of the three participating hospitals, was based on a consecutive series of 314 patients undergoing surgery for colorectal cancer between January 1986 and May 2001. All patients were considered sporadic cases because those with familial adenomatous polyposis and clinical criteria for hereditary non-polyposis colorectal cancer (Amsterdam criteria) were excluded. Tumour samples and corresponding normal tissues consisted of 63 paired samples that were formalin fixed and paraffin embedded, and 251 snap frozen tissues.

All tumours were examined histologically by two pathologists to: (a) confirm the diagnosis of adenocarcinoma, (b) confirm the presence of tumour and evaluate the percentage of tumour cells in these samples, and (c) carry out pathological staging. All samples had at least $75 \%$ tumour cells. To ascertain whether contamination of the tumour samples by normal cells could affect allelic signal intensity in terms of the value considered to indicate the presence of LOH, 30 tumour samples were randomly selected and any normal tissue was removed by micro dissection. Subsequently, DNA was extracted from microdissected and non-microdissected paired tumour samples, and the $\mathrm{LOH}$ analysis described below was performed to assess the possible correlation between the two sets of results.

DNA from tumour and corresponding normal tissues was extracted from formalin fixed paraffin embedded tissues using chelatin resin, or from snap frozen tissues using a nonorganic method (S-4520 Kit; Oncor Inc., Gaithersburg, Maryland, USA).

\section{Clinicopathological characteristics}

The medical records of the 314 patients provided birth date and sex, and the following parameters: tumour location, tumour size, lymph node metastases, pathological stage, vascular invasion, tumour differentiation, and carcinoembryonic antigen (CEA) levels. Pathological stage was assessed using the tumour, node, and metastases classification system. All tumours were graded for percentage glandular appearance. CEA levels were determined by a microparticle enzyme immunoassay method (AXSYM CEA; Abbott, Wiesbaden, Germany) and the range $0-5 \mathrm{ng} / \mathrm{ml}$ was considered normal.

Follow up was based on regular (every three months during the first year, every six months during the second year, and then yearly until relapse) clinical, biochemical (including CEA levels), and radiological examination, and yearly endoscopy. The starting point for DFS time was the date of surgery, and the end was the date of relapse. Overall survival was the interval between the date of surgery and the last visit or death.

\section{PCR conditions, primers, and LOH assay BRCA1 locus}

Allelic deletions were detected by LOH analysis using the microsatellite markers D17S1323, D17S1322, and D17S855, which localise to introns 12,19 , and 20, respectively. ${ }^{23}$ Polymerase chain reaction (PCR) was performed in $25 \mu \mathrm{l}$ volumes using 0.2 units of Taq Gold DNA polymerase and $1 \times$ PCR buffer (Perkin-Elmer, Roche Molecular Systems, Inc., Branchburg, New Jersey, USA), $200 \mu \mathrm{M}$ dNTPs, 30 pmol of each primer, and different concentrations of $\mathrm{KCl}$ and $\mathrm{MgCl}_{2}$ depending on the polymorphic marker used. PCR was performed in a thermocycler (Perkin-Elmer, Cetus, Foster City, California, USA). Each sample was denatured at $94^{\circ} \mathrm{C}$ for 11 minutes and subjected to 30 cycles (denaturation at $94^{\circ} \mathrm{C}$ for 30 seconds, annealing at $56^{\circ} \mathrm{C}$ for 40 seconds, and elongation at $72^{\circ} \mathrm{C}$ for 30 seconds) followed by a final
12 minute extension at $72^{\circ} \mathrm{C}$. The amplified products were mixed with $6 \mu \mathrm{l}$ of loading buffer $(0.02 \%$ xylene cyanol, $0.02 \%$ bromophenol blue) and run on non-denaturing $8 \%$ polyacrylamide gels for four hours at $500 \mathrm{~V}$. Following gel electrophoresis, allelic band intensity was detected by a nonradioisotope technique using a commercially available silver staining method. ${ }^{24}$

\section{TP53 region, 17p13}

Using two polymorphic markers of the $17 \mathrm{p} 13$ region, TP53.6, ${ }^{25}$ intragenic to PT53, and D17S786, ${ }^{26}$ centromeric to TP53, a LOH study was performed in an LOH assay similar to the one above, with specific annealing temperatures of $59^{\circ} \mathrm{C}$ and $58^{\circ} \mathrm{C}$ for each marker.

\section{Analysis of $\mathrm{LOH}$}

Allele intensities were analysed by densitometry. The gel image was captured using a GS-690 Imaging Densitometer (Bio-Rad Laboratories, Hercules, California, USA), digitised at $400 \mathrm{dpi}$ and analysed using Multi-Analyst/PC (Bio-Rad Laboratories). In this study, $\mathrm{LOH}$ was considered to exist when the allele signal was over $75 \%$ less than in the normal counterpart DNA (fig 1). In the 30 tumours studied after microdissection, there were no determinable decreases in allelic signal intensity to below our $75 \%$ cutoff point. All samples maintained a range of signal intensity similar to that exhibited prior to microdissection. Microsatellite instability (MI) was considered to be present when there were mobility shifts in tumour bands in at least one marker; as only five markers were used some cases could be microsatellite stable tumours. Samples with MI were excluded from the studies.

\section{Statistical analyses}

Variables analysed were compared using the $\chi^{2}$ test with Yates' correction, or Fisher's exact test when any of the expected frequencies was less than 5 . Two tailed $\mathrm{p}$ values $<0.05$ were considered statistically significant. Univariate survival analyses were performed to determine which independent variables were predictors of recurrence. The survival distributions were calculated using the Kaplan-Meier product limit method. Overall survival time was defined as the interval between the date of diagnosis and tumour related death, or the last visit if the patient survived. Hypotheses on the differences between groups were tested using the log rank test. Multivariate analysis used Cox's model to identify the factors involved in the outcome. Statistical analysis used the SPSS v10.0 for Windows (computer software package; SPSS Inc., USA). Relative risk was calculated for all factors, with $95 \%$ confidence interval (CI).

\section{RESULTS}

In this series of 314 patients, $26(8.3 \%)$ showed MI in at least one of the polymorphic markers studied and were eliminated from the study to avoid misinterpretation of the results (table 1); $244(84.7 \%)$ of the 288 eligible cases were informative.

\section{LOH rate and clinicopathological characteristics}

Of the 244 informative cases, 97 patients $(39.8 \%)$ showed $\mathrm{LOH}$ in at least one of the markers used. Results for each locus are summarised in table 2 .

The sex distribution in our series of informative patients was as follows: $146(60 \%)$ were male, of whom $58(39.7 \%)$ showed LOH; and 98 (40\%) were female, with $39(39.7 \%)$ showing LOH. Median age was 70 (11) years for the entire series, and 71 (11) years and 70 (10) years for patients with and without $\mathrm{LOH}$, respectively. CEA levels and histopathological tumour characteristics and their distribution are 

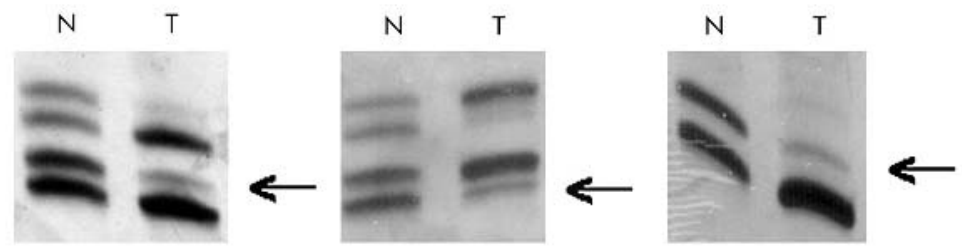

D17S1322
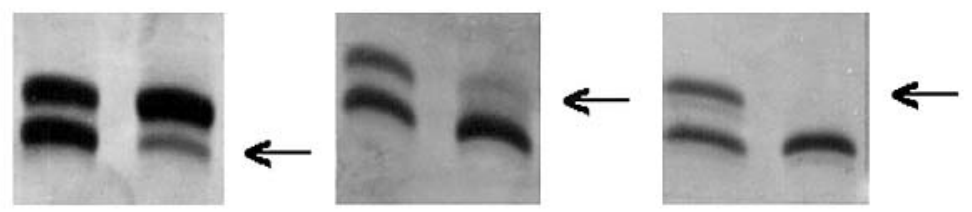

D17S855
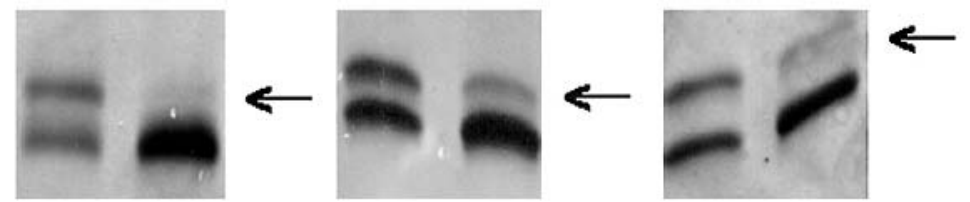

Figure 1 Photographs of gels taken under normal light after staining with an $\left(\mathrm{NO}_{3}\right) \mathrm{Ag}$ method, showing examples of loss of heterozygosity at different loci studied in the BRCA1 gene locus (17q21 region). N, normal tissue; T, tumour. Arrows indicate allelic loss in tumour DNA.

summarised in table 3. When the incidence of LOH in each of the subgroups was analysed in terms of pathological characteristics, no significant differences were observed (tables 3, 4).

\section{Relation to TP53 LOH status}

After screening of the tumour samples with the two polymorphic markers of the TP53 gene region, 159 (50.8\%) cases were informative, of which $78(49 \%)$ tumours showed LOH. In these cases a correlation study between clinicopathological characteristics and $\mathrm{LOH}$ at the locus of this gene, similar to that performed for BRCAl, was done. No significant differences were observed (table 3 ). Informativity was detected in $130(41.4 \%)$ samples for both regions, BRCAl and TP53, but no significant association was demonstrated between allelic deletions in the two regions, suggesting that chromosome 17 is not lost in the majority of cases (table 5).

\section{Recurrence, disease free survival, and overall survival analyses for BRCA 1 LOH}

As no significant association between $\mathrm{LOH}$ and tumour pathological characteristics was found, the relationship of allelic loss with disease relapse, DFS, and overall survival was studied.

Adjuvant chemotherapy with combinations of 5-fluorouracil plus levamisole or 5-fluorouracil plus leucovorin was administered to $38(39.6 \%)$ of the informative stage III

Table 1 Distribution of microsatellite instability (MI) for BRCA1 and TP53 loci

\begin{tabular}{ll}
\hline Marker & MI (\%) \\
\hline D17S855 & $7(27)$ \\
D17S1322 & $5(19)$ \\
D17S1323 & $8(31)$ \\
TP53.6 & $0(0)$ \\
D17S786 & $6(23)$ \\
\hline
\end{tabular}

patients. In these cases the recurrence rate was $12(31.5 \%)$, five cases with $\mathrm{LOH}$ and seven without $\mathrm{LOH}$. No adjuvant chemotherapy was dispensed to any patient with stage II disease. In contrast, a high proportion of stage IV patients received systemic chemotherapy.

The recurrences observed among the informative cases with complete follow up $(\mathrm{n}=214)$ for stages I, II, and III were $51(23.8 \%)$, with a distribution for LOH as follows: 31 $(60.7 \%)$ showed LOH and $20(39.3 \%)$ no LOH $(p=0.0003)$. Analysis of recurrences showed significant differences in the presence of LOH in stages I and II, which disappeared at stage III (table 6).

DFS of patients was $63.3 \%$ (SEM 4.6) at five years. The presence of $\mathrm{LOH}$ had a statistically significant impact on DFS $(p=0.0004)$, with a DFS rate of $73.3 \%$ (SEM 5.7) at five years in patients without LOH and $49.2 \%$ (SEM 7.1) in cases with positive allelic loss (fig 2 ). In the study by stages of DFS and LOH status, the Kaplan-Meier curves established the following results; in stage I, a difference between patients with $\mathrm{LOH}$ and patients without allelic loss $(p=0.03)$ was observed; in stage II, a clearer difference than in stage I was determined, with shorter DFS in patients with $\mathrm{LOH}(\mathrm{p}=0.001)$; and in stage III, these differences disappeared $(p=0.38)$ (fig 3$)$.

When DFS was analysed for pathological tumour characteristics, tumour differentiation, vascular invasion, stage, lymph node metastases, and tumour location, stage III

Table 2 Informativity and loss of heterozygosity $(\mathrm{LOH})$ for each marker at the BRCAl gene locus

\begin{tabular}{lll}
\hline Marker & Informative cases & LOH (\%) \\
\hline D17S855 & 178 & $62(34.8)$ \\
D17S1322 & 167 & $55(32.9)$ \\
D17S1323 & 124 & $44(35.5)$ \\
Overall I* & 244 & $97(39.8)$ \\
Overall II† & 103 & $41(39.8)$ \\
Overall III & 52 & $18(34.6)$ \\
\hline
\end{tabular}

*Patients with at least one informative marker; tpatients with two informative markers; fpatients with three informative markers. 
Table 3 Relationship between allelic loss at the TP53 gene locus and clinicopathological characteristics

\begin{tabular}{|c|c|c|c|c|}
\hline Characteristic & Informative tumours & With LOH (\%) & Without LOH (\%) & p Value \\
\hline Patients ( $n$ ) & 159 & $78(49)$ & $81(51)$ & - \\
\hline Age $(y)^{*}$ & 71 (9.8) & $70.5(9.8)$ & $71(10)$ & - \\
\hline \multicolumn{5}{|l|}{ Sex } \\
\hline Male & $96(60.5)$ & $51(53)$ & $45(47)$ & \\
\hline Female & $63(39.5)$ & $27(43)$ & $36(57)$ & 0.26 \\
\hline \multicolumn{5}{|l|}{ Tumour side } \\
\hline Right & 39 (23.9) & $20(53)$ & $18(47)$ & \\
\hline Left & $60(37.8)$ & $32(53)$ & $28(47)$ & \\
\hline Rectum & 61 (38.3) & $26(43)$ & 35 (57) & 0.44 \\
\hline \multicolumn{5}{|l|}{ Stage } \\
\hline 1 & $13(7.9)$ & $3(23)$ & 10 (77) & \\
\hline$\|$ & 77 (48.7) & $44(57)$ & $33(43)$ & \\
\hline III & $59(36.8)$ & $26(44)$ & $33(56)$ & \\
\hline IV & $10(6.6)$ & $5(50)$ & $5(50)$ & 0.10 \\
\hline \multicolumn{5}{|c|}{ Vascular invasion } \\
\hline Yes & $79(49.5)$ & $33(42)$ & $46(58)$ & \\
\hline No & $80(50.5)$ & $45(56)$ & $35(44)$ & 0.09 \\
\hline \multicolumn{3}{|l|}{ Polyps } & $23(44)$ & \\
\hline- & $107(67.3)$ & $49(48)$ & $58(52)$ & 0.31 \\
\hline \multicolumn{5}{|l|}{ CEA } \\
\hline $0-5 \mathrm{ng} / \mathrm{ml}$ & $76(48.1)$ & 37 (49) & $39(51)$ & \\
\hline$>5 \mathrm{ng} / \mathrm{ml}$ & 28 (17.7) & $14(50)$ & $14(50)$ & 0.09 \\
\hline Unknown & 55 (34.2) & $27(49)$ & $28(51)$ & \\
\hline \multicolumn{5}{|c|}{ Lymph node metastases } \\
\hline Negative & $98(61.5)$ & $50(51)$ & $48(49)$ & \\
\hline $1-3$ & $41(25.9)$ & $21(51)$ & $20(49)$ & 0.40 \\
\hline 4 & $20(12.6)$ & $7(35)$ & $13(65)$ & \\
\hline \multicolumn{5}{|c|}{ Tumour differentiation } \\
\hline Well & $56(35)$ & $26(46)$ & $30(54)$ & \\
\hline Moderate & $76(48)$ & $42(55)$ & $34(45)$ & 0.23 \\
\hline Poor & 27 (17) & $10(37)$ & $17(63)$ & \\
\hline
\end{tabular}

*Values are median (SEM). All other values are number (\%).

$\mathrm{LOH}$, loss of heterozygosity; CEA, carcinoembryonic antigen.

Table 4 Relationship between allelic loss at the BRCA1 gene locus and clinicopathological characteristics

\begin{tabular}{|c|c|c|c|c|}
\hline Characteristic & Informative fumours & With LOH (\%) & Without LOH (\%) & p Value \\
\hline Patients (n) & 244 & $97(39.8)$ & $147(60.2)$ & - \\
\hline Age $(y)^{*}$ & 70 (11) & $71(11)$ & $70(10)$ & - \\
\hline \multicolumn{5}{|l|}{ Sex } \\
\hline Male & $146(60)$ & $58(39.7)$ & $88(60.2)$ & \\
\hline Female & $98(40)$ & $39(39.7)$ & $59(60.3)$ & 0.84 \\
\hline \multicolumn{5}{|l|}{ Tumour side } \\
\hline Right & $55(22.5)$ & $18(32.7)$ & $37(67.3)$ & \\
\hline Left & $100(41)$ & $45(45)$ & $55(55)$ & \\
\hline Rectum & $89(36.5)$ & $34(38.3)$ & 55 (61.7) & 0.30 \\
\hline \multicolumn{5}{|l|}{ Stage } \\
\hline 1 & 30 (12.3) & $11(36.7)$ & $19(63.3)$ & \\
\hline$\|$ & $102(41.8)$ & $36(35.3)$ & 66 (64.7) & \\
\hline IIII & $94(38.5)$ & $40(42.6)$ & $54(57.4)$ & \\
\hline IV & $18(7.4)$ & $10(55.6)$ & $8(44.4)$ & 0.37 \\
\hline \multicolumn{5}{|c|}{ Vascular invasion } \\
\hline Yes & $118(48.3)$ & $46(39)$ & $72(61)$ & \\
\hline No & $126(51.7)$ & $51(40.5)$ & 75 (59.5) & 0.91 \\
\hline \multicolumn{5}{|l|}{ Polyps } \\
\hline+ & $75(30.8)$ & $29(39)$ & $46(61)$ & \\
\hline- & $169(69.2)$ & $69(40.5)$ & $100(59.5)$ & 0.81 \\
\hline \multicolumn{5}{|l|}{ CEA } \\
\hline $0-5 \mathrm{ng} / \mathrm{ml}$ & $113(46.3)$ & $44(40)$ & $69(60)$ & \\
\hline$>5 \mathrm{ng} / \mathrm{ml}$ & $46(18.9)$ & $18(39)$ & $28(61)$ & 0.94 \\
\hline Unknown & 85 (34.8) & $35(40)$ & $50(60)$ & \\
\hline \multicolumn{5}{|c|}{ Lymph node metastases } \\
\hline Negative & $137(56.1)$ & $53(38.7)$ & $84(61.3)$ & \\
\hline $1-3$ & $71(29.1)$ & $30(42.3)$ & $41(57.7)$ & 0.87 \\
\hline$\geqslant 4$ & $36(14.8)$ & $14(38.9)$ & $22(61.1)$ & \\
\hline \multicolumn{5}{|c|}{ Tumour differentiation } \\
\hline Well & $76(31.1)$ & $27(35.5)$ & $49(64.5)$ & \\
\hline Moderate & $124(50.8)$ & $49(39.5)$ & $75(60.5)$ & 0.42 \\
\hline Poor & $44(18.1)$ & $21(47.7)$ & $23(52.3)$ & \\
\hline
\end{tabular}

*Values are median (SEM). All other values are number (\%).

$\mathrm{LOH}$, loss of heterozygosity; CEA, carcinoembryonic antigen. 
Table 5 Relationships between loss of heterozygosity $(\mathrm{LOH})$, and status of BRCA1 and TP53 gene regions

\begin{tabular}{lllll}
\hline & \multirow{2}{*}{\begin{tabular}{l} 
Informative cases: \\
\cline { 3 - 4 }
\end{tabular}} & \multicolumn{2}{l}{ TP53 region } & \\
\cline { 3 - 4 } & 130 & With LOH & Without LOH & p Value \\
\hline BRCA1 & With LOH & 23 & 20 & 0.66 \\
region & Without LOH & 43 & 44 & \\
\hline
\end{tabular}

$\mathrm{LOH}$, loss of heterozygosity.

$(\mathrm{p}=0.007)$ and lymph node metastases $(\mathrm{p}=0.001)$ were found, as expected, to affect DFS.

Overall survival of patients was 75\% at five years (95\% CI $67 \%-83 \%$ ). When this survival was analysed for the status of $\mathrm{LOH}$ at the BRCAI locus, we found a significant difference between cases with $\mathrm{LOH}$ and without allelic loss $(\mathrm{p}=0.02)$ of $83 \%$ (95\% CI $75 \%-91 \%)$ and $64 \%$ (95\% CI $50 \%-78 \%)$, respectively (fig 4). Analysis of survival by stages revealed that in stages I and III there were no differences for the presence or absence of $\mathrm{LOH}$, but that $\mathrm{LOH}$ was present in stage II $(p=0.01)$. In stage IV, the significance was inverted $(p=0.03)$ in favour of cases without BRCAl LOH; of 15 patients who died, eight had no allelic loss. Median survival was 3.17 (0.3) months in patients without BRCAl LOH and 12.2 (5) months in cases with BRCAl LOH (fig 5).

\section{Univariate and multivariate analyses}

A univariate analysis was performed to determine the influence of the molecular and pathological variables on DFS. It revealed that of the six variables analysed, only pathological stage, BRCAl LOH, and lymph node metastases had a significant prognostic impact (table 7).

In the multivariate Cox's regression model for DFS, the variables that showed an independent prognostic factor were as follows: stage $(p=0.006) ; \geqslant 4$ positive lymph nodes $(\mathrm{p}=0.0001)$; and $1-3$ lymph nodes affected $(\mathrm{p}=0.038)$ (table 8). However, when we performed specifically the multivariate analysis stratified by stages, the only variable observed with independent prognostic value for DFS was $B R C A l \mathrm{LOH}$ in stages I and II. Patients with BRCAl LOH had a risk ratio of recurrence of 7.04 (95\% CI 2.3-21.3; $\mathrm{p}=0.001)$.

\section{DISCUSSION}

The current prognostic factor in CRC, of proven practical clinical use, is pathological staging. Consequently, five year survival of stage I patients, close to $90 \%$, contrasts with less than $10 \%$ for stage IV patients. However, between $50 \%$ and $80 \%$ of patients in stage II can reach five year survival, with a disease rate recurrence of $20 \%-30 \% .^{1}$ In patients with stage

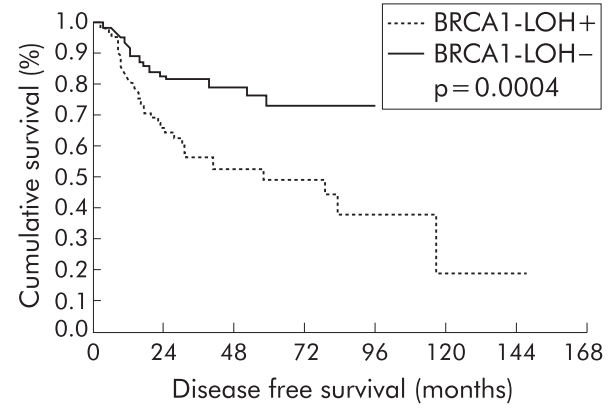

Figure 2 Kaplan-Meier disease free survival curves for the entire series, in relation to BRCA1 loss of heterozygosity $(\mathrm{LOH})$.

III disease, five year survival decreases to $30 \%-50 \%$, although it is possible to achieve a significant improvement in survival with adjuvant chemotherapy based on 5-fluorouracil and levamisole ${ }^{27}$ or 5 -fluorouracil and leucovorin. ${ }^{28}$

The controversy about adjuvant treatment in stage II CRC is currently unresolved. The IMPACT B2 study pooled results from five trials in Dukes' B2 colon cancer patients. These did not support any benefit in five year overall survival; $80 \%$ in the control group and $82 \%$ in the 5 -fluorouracil and leucovorin group. ${ }^{29}$ However, the four NSABP adjuvant studies showed a decreased risk of death with adjuvant treatment similar to the benefit obtained in stage $C^{30}$ Another Dutch study reported a beneficial effect of 5 -fluorouracil and levamisole adjuvant therapy in stage II patients, similar to the expected benefit in stage III. ${ }^{31}$ In stage II patients with high risk clinicopathological characteristics (intestinal obstruction, perforation, tumour adherence, poor differentiation, vascular or lymphatic invasion), adjuvant therapy can reasonably be offered.

The 1994 communication by the Breast Cancer Linkage Consortium $^{21}$ of an increased risk of CRC and prostate cancer in members of linked BRCAI families led to new research into $B R C A 1$ gene alterations in these malignancies. As a result, it has been found that some loci on $17 \mathrm{q} 21$, including the $B R C A 1$ locus, are lost in human prostate cancer. ${ }^{32}{ }^{33}$ In a similar study we detected ${ }^{22}$ a high proportion of allelic deletions in the $17 \mathrm{q} 21$ region in a series of CRCs. However, loss of BRCAl function, if it exists, may be caused by other genetic or epigenetic mechanisms, such as somatic mutations of BRCAl, which are unlikely, or hypermethylation of BRCAl promoter, as has been described in breast and ovarian cancers. $^{34}$

The overall LOH observed in 97 (39.8\%) cases, although lower than in a previous study using seven polymorphic

\begin{tabular}{|c|c|c|c|c|}
\hline & Informative cases (\%) & With LOH (\%) & Without LOH (\%) & p Value \\
\hline \multicolumn{5}{|c|}{ Overall recurrences } \\
\hline Yes & $51(23.8)$ & $31(60.8)$ & $20(39.2)$ & \multirow{2}{*}{0.0003} \\
\hline No & $163(76.2)$ & $53(32.5)$ & $110(67.5)$ & \\
\hline \multicolumn{5}{|c|}{ Stage I } \\
\hline Yes & $5(17.2)$ & $5(100)$ & 0 & \multirow[t]{2}{*}{0.008} \\
\hline No & 24 (82.8) & $6(25)$ & $18(7.5)$ & \\
\hline \multicolumn{5}{|l|}{ Stage II } \\
\hline Yes & 14 (14.6) & 10 (71.4) & $4(28.6)$ & \multirow[t]{2}{*}{0.01} \\
\hline No & $82(85.4)$ & $26(31.7)$ & $56(68.3)$ & \\
\hline \multicolumn{5}{|c|}{ Stage III } \\
\hline Yes & $32(36)$ & $16(50)$ & $16(50)$ & \multirow[t]{2}{*}{0.32} \\
\hline No & 57 (64) & $21(36.8)$ & 36 (73.2) & \\
\hline
\end{tabular}



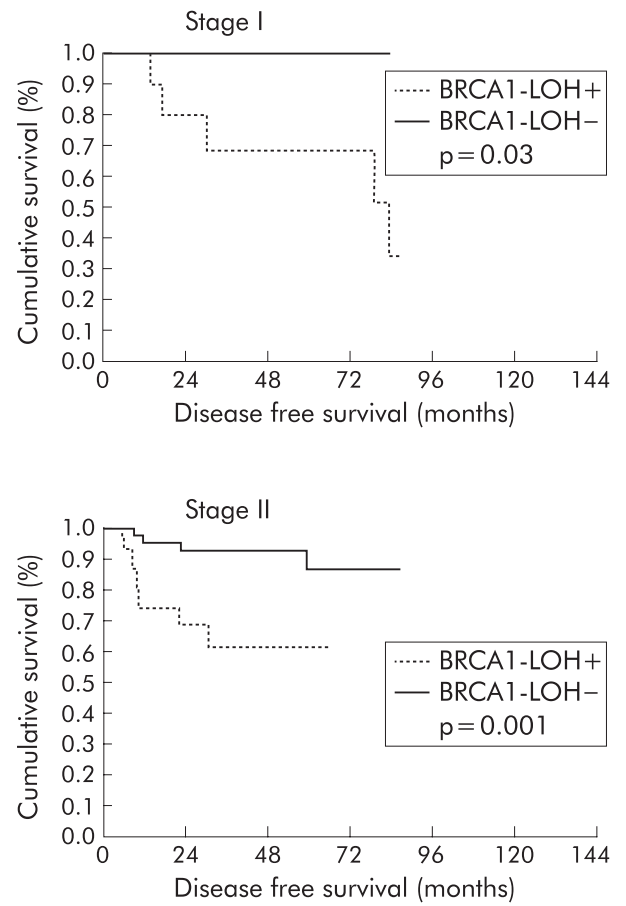

Figure 3 Kaplan-Meier disease free survival curves for patients with stage I and II disease, with reference to allelic loss (LOH) at the BRCAI locus.

markers, ${ }^{22}$ is consistent with the percentage of $\mathrm{LOH}$ reported by some studies of breast cancer, ${ }^{35}{ }^{36}$ which is considered the prototype tumour for $B R C A l$ gene analyses. Considering that the three polymorphic markers used are intragenic to BRCAl, it is impossible to ensure that other genes surrounding the $B R C A 1$ locus are not involved in CRC, as has been suggested in other reports on $\mathrm{LOH}$ on chromosome 17 in CRC. ${ }^{37} 38$ Because the molecular target is located at chromosome 17, BRCAl locus, we judged that TP53 could be the gene functionally most related to CRC. We thus attempted to assess the level of association with $\mathrm{LOH}$ at the BRCAl locus. It was important to establish that the loss at locus TP53 or even the loss of the entire chromosome 17 concomitant with the loss at BRCAl was not a statistically significant association.

Analysis of DFS and overall survival showed the most interesting results. The difference in the entire series for DFS (except stage IV cases) between patients with BRCAl LOH and patients without allelic losses was significant, a difference that was also conserved in the individual analysis by stage, except for stage III. It is possible that at stage III, the biological effect of loss of alleles at the BRCAl locus, if it

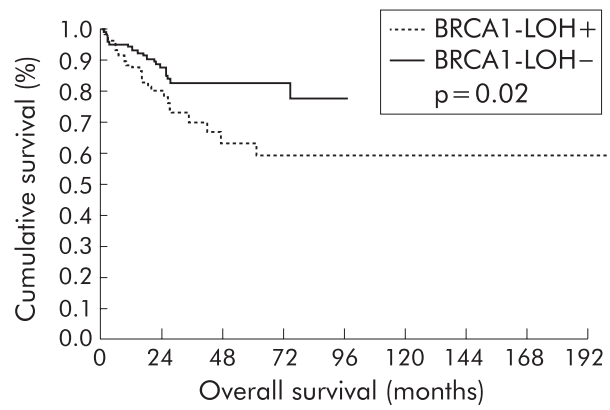

Figure 4 Kaplan-Meier curves of overall survival of the entire series for retention of the BRCA1 alleles. $\mathrm{LOH}$, loss of heterozygosity.
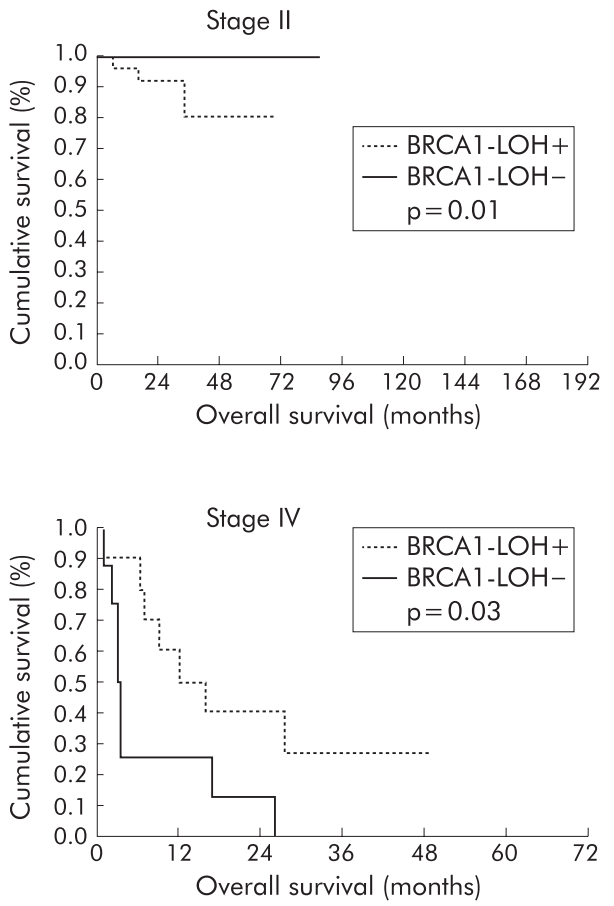

Figure 5 Kaplan-Meier overall survival curves for patients with stage II and IV disease, with the presence or absence of BRCA1 loss of heterozygosity (LOH) in their tumours.

occurred, was surmounted by other molecular changes. The results of the univariate analysis support this possible influence of $\mathrm{LOH}$ at $B R C A \mathrm{l}$, because this molecular alteration displayed a risk ratio for DFS similar to that expressed by the recognised prognostic parameters of colon cancer, such as advanced stage and lymph node metastases. ${ }^{1}$ It is important to emphasise that although the multivariate study of the whole series did not show LOH in BRCAl to be a determining factor in DFS, the study by stages showed that this variable was an independent prognostic factor in stages I and II.

Our BRCAl LOH status results for survival, overall and by stage, were in parallel with the DFS results, except for stage IV. At this stage, the improved survival of cases with $\mathrm{LOH}$ at BRCAl appears paradoxical, and could be secondary to other mechanisms. Stage IV tumours may be the last stage in tumour progression, with accumulation of molecular alterations, ${ }^{39}$ or some stage IV tumours may be different forms of the disease with a specific molecular signature, as observed in comparative genomic hybridisation studies. ${ }^{40}$ In both situations it is conceivable that the particular molecular status may influence treatment response and patient survival.

Studies analysing the impact of several molecular alterations on DFS and overall survival in CRC suggest that genes mapped at regions $18 \mathrm{q}, 17 \mathrm{p}$, and $5 \mathrm{q}$ can be considered potential molecular prognostic indicators. ${ }^{14} 41-44$ Some authors have documented that stage II tumours have a similar prognosis to stage III when they present $\mathrm{T}_{4}$ lesions, a high $\mathrm{S}$ phase, or $18 \mathrm{q}$ deletions. ${ }^{41}$ The $18 \mathrm{q}$ region can represent an important genetic cluster in CRC because three genes located in this region are currently potential gene targets: $D C C$, SMAD4, and SMAD2. ${ }^{45}$ Thus knowledge of the functional significance of BRCAl protein is increasing, ${ }^{17}$ and some of its demonstrated functions, such as regulation of $\mathrm{p} 53$ responsive genes $\left(\mathrm{p} 21^{\text {Wafl }}\right),{ }^{46}$ control of recombination and genome integrity, ${ }^{16}$ or coactivator for $\mathrm{p} 53,{ }^{18}$ if lost or decreased, could be involved in processes of tumorigenesis in general, not only in breast carcinomas. 
Table 7 Disease free survival (univariate Cox's regression model)

\begin{tabular}{|c|c|c|c|c|}
\hline Variable & Category & RR & $95 \% \mathrm{Cl}$ & p Value \\
\hline BRCA1 LOH & Positive $v$ negative & 2.54 & $1.45-4.48$ & 0.001 \\
\hline Vascular invasion & Yes $v$ no & 1.33 & $0.76-2-36$ & 0.31 \\
\hline \multirow[t]{2}{*}{ Tumour side } & Left $v$ right & 1.35 & $0.6-3$ & 0.46 \\
\hline & Rectum $v$ right & 1.31 & $0.66-3$ & 0.52 \\
\hline \multirow[t]{2}{*}{ Stage } & $\| v \mid$ & 1.07 & $0.38-3$ & 0.88 \\
\hline & $|I| v \mid$ & 2.43 & $0.94-6.26$ & 0.05 \\
\hline \multirow[t]{2}{*}{ Tumour differentiation } & Moderate $v$ well & 1.09 & $0.57-2.08$ & 0.78 \\
\hline & Poor $v$ well & 1.64 & $0.75-3.60$ & 0.21 \\
\hline \multirow[t]{2}{*}{ Lymph node metastases } & $1-3 \vee 0$ & 1.90 & $1.02-3.54$ & 0.04 \\
\hline & $\geqslant 4 \vee 0$ & 3.44 & $1.63-7.25$ & 0.001 \\
\hline
\end{tabular}

Table 8 Factors influencing recurrence (multivariate Cox's regression model)

\begin{tabular}{lllll}
\hline Variable & Category & RR & $95 \%$ Cl & p Value \\
\hline Stage & III $v$ I & 4.6 & $1.56-13.56$ & 0.006 \\
Lymph node metastases & $\geqslant 4 v 0$ & 3.83 & $1.81-8.11$ & 0.0001 \\
& $1-3 v 0$ & 0.44 & $0.21-0.95$ & 0.038 \\
\hline
\end{tabular}

$\mathrm{RR}$, risk ratio; $\mathrm{Cl}$, confidence interval; $\mathrm{LOH}$, loss of heterozygosity.

Adjuvant chemotherapy is one of the main factors affecting DFS in stage III. Although no significant difference in DFS in stage III arose from BRCAl LOH status, if adjuvant chemotherapy is given, such a difference cannot be ruled out. Nevertheless, among the 38 stage III patients receiving adjuvant chemotherapy, the proportion of recurrences detected was not significantly different from the remaining stage III patients not receiving adjuvant treatment, although it is possible that the small number of patients analysed may have influenced this result. However, other studies have claimed a possible influence of allelic deletions on the chemotherapy effect although results have not been conclusive. ${ }^{142}{ }^{44}$ Further studies are required.

These results on the proportion of recurrences, and the improvement in DFS and overall survival in patients with retention of BRCAI alleles, suggest that BRCAI LOH may be an independent prognostic factor in patients with CRC, in stages I and II. It may well have a use in stage II to identify patient subgroups at high risk with a poor prognosis who might benefit from adjuvant chemotherapy.

\section{ACKNOWLEDGEMENTS}

We are grateful to Robin Rycroft for his assistance with the English, and E Fernandez, MC Farelo, and PC Zalallos for help with the collection of tissue samples. Supported by grants from Fundación Banco Santander Central Hispano, SEOM, and Bristol-Myers, SA.

\section{Authors' affiliations}

J M Garcia, G Dominguez, J M Silva, J Silva, Molecular Genetics Unit, Hospital Universitario Puerta de Hierro, Madrid, Spain

R Rodriguez, Department of Pathology, Hospital Virgen de la Salud, Toledo, Spain

M Provencio, P España, F Bonilla, Department of Medical Oncology, Hospital Universitario Puerta de Hierro, Madrid, Spain

A Colmenarejo, Medical Oncology Service, Hospital Militar del Aire, Madrid, Spain

I Millan, Biostatistics Unit, Hospital Universitario Puerta de Hierro, Madrid, Spain

C Muñoz, Gastroenterology Service, Hospital Virgen de la Salud, Toledo, Spain

C Salas, Department of Pathology, Hospital Universitario Puerta de Hierro, Madrid, Spain

S Coca, Department of Pathology, Hospital Militar del Aire, Madrid, Spain

\section{REFERENCES}

1 Cohen AM, Minsky BD, Schilsky RL. Cancer of the colon. In: Devita VT jr, Hellman S, Rosemberg SA, eds. Cancer principles and practice of oncology. Philadelphia: Lippincott-Raven, 1997: 1 144-97.

2 Deans GT, Parks TG, Rowlands BJ, et al. Prognostic factors in colorectal cancer. Br J Surg 1992;79:608-13.

3 Silverberg E, Boring CE, Squires TS. Cancer statistics. CA Cancer J Clin 1990:40:9-26.

4 Vogelstein B, Fearon ER, Hamilton SR, et al. Genetics alterations during colorectal-tumor development. N Engl J Med 1988;319:525-32.

5 Delattre O, Olschwang S, Law DJ, et al. Multiple genetics alterations in distal and proximal colorectal cancer. Lancet 1989:12:353-6.

6 Vogelstein B, Fearon ER, Kern SE, et al. Allelotype of colorectal carcinoma. Science 1989;244:207-11.

7 Solomon E, Voss R, Hall V, et al. Chromosome 5 allele loss in human colorectal carcinomas. Nature 1987;328:616-19.

8 Ashton-Rickardt PG, Dunlop MG, Nakamura Y, et al. High frequency of APC loss in sporadic colorectal carcinoma due to breaks clustered in 5q21-22. Oncogene 1989;4:1169-74.

9 Fearon ER, Cho KR, Nigro JM, et al. Identification of a chromosome 18q gene that is altered in colorectal carcinoma. Science 1990;247:49-56.

10 Baker SJ, Fearon ER, Nigro JM, et al. Chromosome 17 deletions and p53 gene mutations in colorectal carcinoma. Science 1989;244:217-21.

11 Kellsell DP, Spurr NK, Barnes DM, et al. Combined loss of BRCA1/BRCA2 in grade 3 breast carcinomas. Lancet 1996:347:1554-5.

12 Backmann MW, Picard F, An HX, et al. Clinical impact of loss of heterozygosity of BRCA1 and BRCA2 markers in sporadic breast cancer. Br J Cancer 1996;73:1220-6.

13 Silva JM, Gonzalez R, Provencio M, et al. Loss of heterozygosity in BRCA1 and BRCA2 markers and high-grade malignancy in breast cancer. Breast Cancer Res Treat 1999;53:9-17.

14 Kern SE, Fearon ER, Tersmette KWF, et al. Clinical and pathological associations with allelic loss in colorectal carcinoma. JAMA 1989:261:3099-103.

15 Martínez-López E, Abad A, Monzó M, et al. Allelic loss on chromosome 18q as a prognostic marker in stage II colorectal cancer. Gastroenterology 1998;114:1180-7.

16 Chapman MS, Verma MI. Transcriptional activation by BRCA1. Nature 1996:382:678-9

17 Scully R, Chen J, Plug A, et al. Association of BRCA1 and Rad51 in mitotic and meiotic cells. Cell 1997;88:265-75.

18 Scully R, Livingston DM. In search of the tumor-suppressor functions of BRCA1 and BRCA2. Nature 2000;408:429-32.

19 Ouchi T, Monteiro ANA, August A, et al. BRCA1 regulates p53-dependent gene expression. Proc Natl Acad Sci U S A 1998;95:2302-6.

20 Newman B, Mu H, Butler LM, et al. Frequency of breast cancer attributable to BRCA1 in a population-based series of American women. JAMA 1998;279:915-21.

21 Ford D, Easton D, Bishop D, et al. Risk of cancer in BRCA 1-mutation carriers. Lancet 1994;343:692-5

22 García-Patiño E, Gomendio B, Lleonart M, et al. Loss of heterozygosity in the region including the BRCA1 gene on $17 q$ in colon cancer. Cancer Genet Cytogen 1998;104:19-23.

23 Smith TM, Lee MK, Szabo Cl, et al. Complete genomic sequence and analysis of $117 \mathrm{~kb}$ of human DNA containing the gene BRCA1. Genome Res 1996:6:1029-49. 
24 Oto M, Miyake S, Yuasa Y. Optimization of nonradioisotopic single strand conformation polymorphism analysis with a conventional minislab gel electrophoresis apparatus. Ann Biochem 1993;213:19-22.

25 Deng G, Lu Y, Zlotnikov G, et al. Loss of heterozygosity in normal tissue adjacent to breast carcinomas. Science 1996;274:2057-9.

26 Werness BA, Parvatiyar P, Ramus SJ, et al. Ovarian carcinoma in situ with germline BRCA1 mutation and loss of heterozygosity at BRCA1 and TP53. J Nat Cancer Inst 2000;92:1088-91.

$27 \mathrm{NIH}$ consensus conference. Adjuvant therapy for patients with colon and rectal cancer. JAMA 1990;264:1444-50.

28 International Multicentre Pooled Analysis of Colon Cancer Trials (IMPACT) investigators. Efficacy of adjuvant fluorouracil and folinic acid in colon cancer. Lancet 1995;345:939-44.

29 International Multicentre Pooled Analysis of B2 Colon Cancer Trials (IMPACT B2) Investigators. Efficacy of adjuvant fluorouracil and folinic acid in B2 colon cancer. J Clin Oncol 1999;17:1356-63.

30 Mamounas E, Wieand S, Wolmark N, et al. Comparative efficacy of adjuvant chemotherapy in patients with Dukes' B versus Dukes' C colon cancer: Results from four National Surgical Adjuvant Breast and Bowel Project adjuvant studies (C-01, C-02, C-03, and C-04). J Clin Oncol 1999;17:1349-55.

31 Taal BG, Van Tinteren H, Zoetmulder FA. Adjuvant $5 F U$ plus levamisole in colonic or rectal cancer: Improved survival in stage II and III. Br J Cancer 2001;85: 1437-43.

32 Gao X, Zacharek A, Salkowski A, et al. Loss of heterozygosity of the BRCA1 and other loci on chromosome 17p in human prostate cancer. Cancer Res 1995;55:1002-5.

33 Gao X, Zacharek A, Grignon DJ, et al. Localization of potential tumor suppressor loci to $\mathrm{a}<2 \mathrm{Mb}$ region on chromosome $17 \mathrm{q}$ in human prostate cancer. Oncogene 1995;11:1241-7.

34 Esteller M, Silva JM, Domingez G, et al. Promoter hypermethylation and BRCA1 inactivation in sporadic breast and ovarian tumors. J Natl Cancer Inst 2000;92:564-9.
35 Cropp CS, Nevanlinna HA, Pyrhönen S, et al. Evidence for involvement of BRCA1 in sporadic breast carcinoma. Cancer Res 1994;54:2548-51.

36 Gonzalez R, Silva JM, Dominguez G, et al. Detection of loss of heterozygosity at $\operatorname{Rad} 51, \operatorname{Rad} 52, \operatorname{Rad} 54$ and BRCA1 and BRCA2 loci in breast cancer: pathological correlations. Br J Cancer 1999;81:503-9.

37 Leggett B, Young J, Buttenshaw R. Colorectal carcinomas show frequent allelic loss on the long arm of chromosome 17 with evidence for a specific target region. Br J Cancer 1995;71:1070-3.

38 Campo E, Miquel R, Jares $\mathrm{P}$, et al. Prognostic significance of the loss of heterozygosity of NM23- $\mathrm{H} 1$ and p53 genes in human colorectal carcinomas. Cancer 1994;73:2913-21.

39 Claij N, de Riele H. Microsatellite instability in human cancer: A prognostic marker for chemotherapy? Exp Cell Res 1999;246:1-10.

40 Al-Mulla F, Keith WN, Pickford IR, et al. Comparative genomic hybridization analysis of primary colorectal carcinomas and their synchronus metastases. Genes Chromosom Cancer 1999;24:306-14.

41 Jen J, Kim H, Piantadosi S, et al. Allelic loss of chromosome 18q and prognosis in colorectal cancer. N Engl J Med 1994;331:213-21.

42 Watanabe T, Wu TT, Catalano PJ, et al. Molecular predictors of survival after adjuvant chemotherapy for colon cancer. $N$ Engl J Med 2001;344:1196-206

43 Cohn KH, Ornstein DL, Wang F, et al. The significance of allelic deletions and aneuploidy in colorectal carcinoma. Cancer 1997:79:233-44.

44 Carethers JM, Hawn JK, Greenson JK, et al. Prognostic significance of allelic loss at chromosome 18q21 for stage II colorectal cancer. Gastroenterology 1998;114:1188-95.

45 Eppert K, Scherer SW, Ozcelik H, et al. MADR2 maps to 18q21 and encodes a TGF-beta-regulated SMAD-related protein that is functionally mutated in colorectal carcinoma. Cell 1996;86:543-52.

46 Somasundaram K, Zhang $H$, Zeng $Y-X$, et al. Arrest of the cell cycle by the tumor-suppressor BRCA1 requires the CDK-inhibitor P21 WAF1/CIP. Nature 1997;389:187-90. 